\title{
The Comparative Double Blind Clinical Study in Antihelmintic Efficacy Between Thai Traditional Herbal Formulae and Mebendazole
}

\author{
${ }^{1}$ Buavaroon Srichaikul, ${ }^{2}$ Supachai Samappito, ${ }^{3}$ Surapote Wongyai and ${ }^{1}$ Gordon Bakker \\ ${ }^{1}$ Faculty of Public Health, ${ }^{2}$ Department of Biotechnology, \\ Faculty of Technology, Mahasarakham University, 44000 Mahasarakham, Thailand \\ ${ }^{3}$ Faculty of Oriental Medicine, Rungsit University, Thailand
}

\begin{abstract}
This study was carried out in Mahasarakham Primary Healthcare Centre, Mahasarakham province in the area of Northeastern of Thailand. The experiment was randomized control trial clinical study in order to examine the efficacy of TTHF in the treatment of antihelmintic activity of mixed worms infection in human. The experimental group consisted of 10 and 5 patients for control group with inclusion and exclusion criteria which were screened by the selection of mixed worm infection symptoms samples. The investigation and extraction of worm Eggs Per Gram of patient feces method (EPG) were performed with Ether Formalin Sedimentation Test. The percentage of reduction of Eggs Per Gram (EPG) of patient feces were collected, counted and confirmed by parasitologist and the clinical efficacy was investigated by the physician and the pharmacist. The EPG (\%) data were collected before and after the treatment with TTHF and with Mebendazole. The result showed that TTHF had higher efficacy in antihelmintic activity than Mebendazole and placebo which had the reduction (\%) of egg per gram of feces as 93.69 with TTHF and reduction (\%) of egg per gram of feces as 87.50 in Mebendazole. The suggestion of this study should increase the number of samples of worm infected patients which the samples can be identified with the specific helminthes genus and species in order to obtain the efficacy by the treatment using TTHF and Mebendazole comparatively.
\end{abstract}

Key words: Efficacy, Thai traditional herbal formulae, Mebendazole, egg per gram, feces, Thailand

\section{INTRODUCTION}

In the tropical countries such as Thailand, we have a high incidence rate of human parasitic infection which can be very harmful to humans. The initial stage of parasitic infection such as nematode, tapeworm, hook worm do not have sudden severe harmful effects to the human body. The symptoms will develop gradually and slowly which can destroy the internal organs. Some parasites can withdraw blood from human intestines or other internal cell wall organs and also nutrients from human bodies. The patients will slowly lose their weight and turn pale. The patients will also possess a lack of cognitive thinking and less intellect.

About $>32$ countries faced the problems of clean food consumption and clean drinking tap water management supplied to the main population. There are $>12$ million people who suffer from helminthes infection. WHO (World Health Organization) has considered the parasitic problem as one of the major health communicable disease issues in the world. In Thailand the Ministry of Health has launched the project in order to decrease the incidence of food borne diseases, especially parasitic diseases which occurred in people who have less exposed to sanitation of food and water intake. Normally, these patients will contact the parasites through food intake, water intake and skin transmission. One cause is the style of Thai Northeastern food preparation which is involved undercooked foods. The villagers like to consume raw food from fish, pork, beef which promote worm diseases. Another reason is the polluted local drinking water that the people consume on a daily basis from the river which was not clean and was contaminated with bacteria, worms and viruses. WHO is responsible for the record of 133 million of infected worm diseases patients throughout the world.

The indication showed that the numbers of infected patients were under the age $<5$ years mostly. Since, 2006-2011 the incident rate of parasitic human diseases was decreased gradually from $1,051,447-800,000$ patients. The worms which were discovered in Thailand were multi-cellular and one structure. Helminthes live in human body and also in animal body.

They work as possible parasitic condition consuming the nutrients and blood from the body. There are many species of parasites which live in soil, weed, water in the

Corresponding Author: Buavaroon Srichaikul, Faculty of Public Health, Mahasarakham University, 44000 Mahasarakham, Thailand 
fresh of terrestrial, in aquatic, in amphibians, etc. Helminthes can transmit through oral skin absorption and even through placenta movement from mother to baby. Helminthes are tapeworm, strongyloides, liver flukes, lung flukes and some may be travel through skin such as trichunoris.

The patients who was infected may show the symptoms as more food intakes, weight loss, diarrhea, irritable colon, bloating, body pain and blurred vision. The patients should go to see the physician in order to have stool examination test for worm eggs per gram of feces by any method such as Kato Katz Method or Ether-Formalin Sedimentation Test. Some patients have shown the severe symptoms which cause paralysis or death. Types, size, volumes and location of helminthes and also the duration of infection are important for indicating the severity of infection. Some patients exhibit signs of jaundice, liver cirrhosis and result in liver carcinoma.

The side effect of antihelminthic medicines may cause stomachache, diarrhea and irritable colon. Some also cause nausea, vomitting. The research team had introduced Thai Traditional Formula Medicine (TTFM) in the treatment of helminthes and compared the efficacy and side effects among Mebendazole (500 mg). Thai traditional formula medicine consists of 8 herbals which are:

- Terminalia chebula (Retz) (Samao Thai) (Fig. 1)

- Terminalia citrina (Roxb.) (Samao Ted) (Arjun)

- Curcuma zedoaria (Berg) Rosco. (Kamin Aoi) (Fig. 2)

- Terminalia citriva (Gaertn). Roxb. Flem ( Samao Ngu)

- Cuttle bone (Tricosan) (Lintalay)

- Purified water

- Croton tiglium Lin. (Purging croton) (Fig. 3)

- Diospyros mollis (Griff.) (Ebony tree) (Fig. 4)

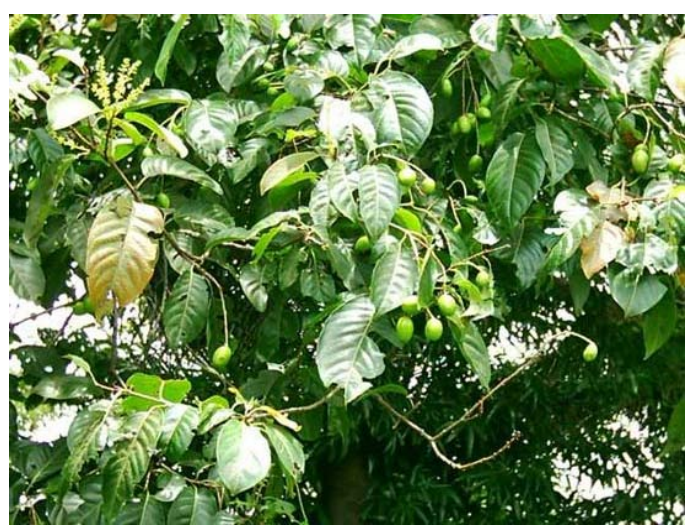

Fig. 1: Terminalia chebula (Retz) ( Samao Thai)
Dosage of TTFM is orally, 3-6 capsules daily before breakfast $(500 \mathrm{mg})$, continue for 3 days. Each of 7 medicinal herbs and purified water is mixed as dry powder in equal portions and was filled into capsules. Mebendazole $500 \mathrm{mg}$ is the drug of choice in treatment of helminthes infection in this research and

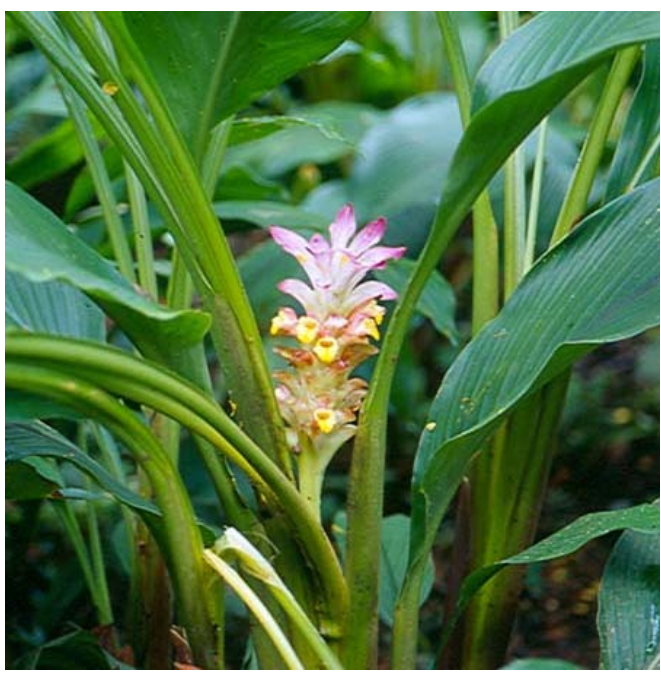

Fig. 2: Curcuma zedoaria (Berg) Rosco. (Kamin Aoi)

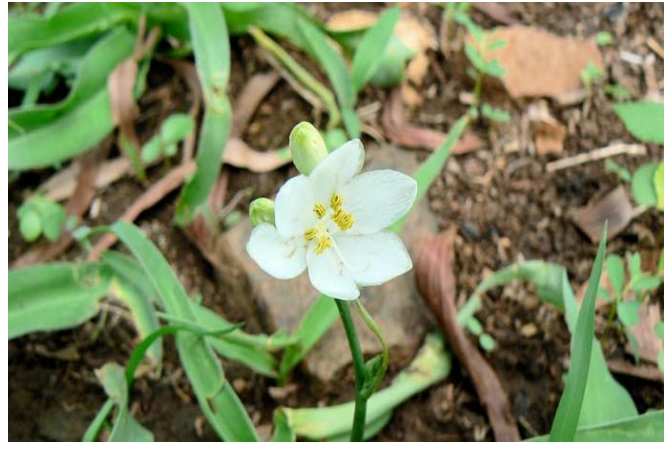

Fig. 3: Croton tiglium Lin. (Purging croton)

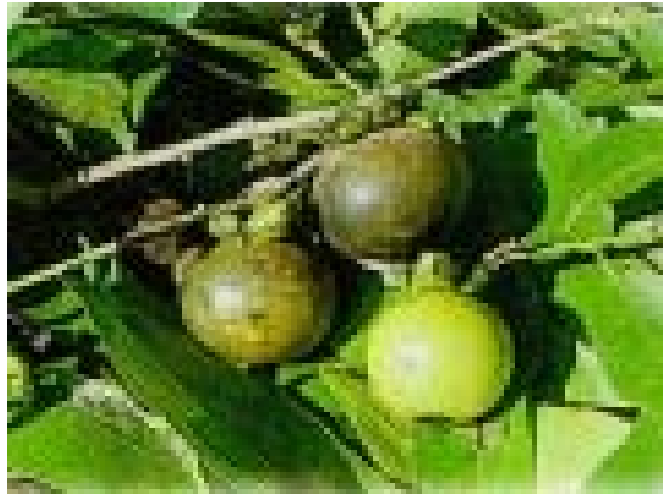

Fig. 4: Diospyros mollis (Griff.) (Ebony tree) 
considered as modern medicine. Dosage form is chewable tablet, $500 \mathrm{mg}$ and taken as once daily for 3 days continuously.

Litrature review: Malinee et al found that the comparative study among Piper nigrum Linn., Areca catechu Linn. and Thai Depree in antihelmintic efficacy comparison in Thailand were used in treatments of mixed infections. The dosages used were $6.5,45.5$ and $6.5 \mathrm{~g}$, respectively and the egg reduction rate were $80-90 \%$.

Fabibi studied the vermicidal herbs in animals which were found in Nigeria. In the year of 2000, WHO had the health policy of promoting herbal medicinal replacements in order to supplement modern medicines which the efficacy were $77 \%$ effective.

Carsten Flohr showed the results of randomized double blind experimental trial in efficacy between Mebendazole $(500 \mathrm{mg})$ and Albendazole showed no difference. If there was the increase of 3 times dosage of both drugs the result showed $75 \%$ in efficacy of Mebendazole and $88 \%$ in Albedazole. The experimental research was carried on and confirmed by Parasitologist, Pharmacists, Physician and nurses. The selection of the patients was considered at the early stage of mixed worm infection diseases.

Sardsaengjun and Jutiviboonsuk (2010) studied the effect of temperature and duration time on polyphenols extract of Areca catechu Linn. Seeds which was found that the study aimed to explore the effect of temperature and duration time on polyphenols content from extracts of areca seeds (Areca catech $u$ Linn.). The extractions were performed at 3 different temperatures $\left(60,80\right.$ and $\left.100^{\circ} \mathrm{C}\right)$ and 4 different duration times $(15,30,45$ and $60 \mathrm{~min})$. It was found that temperature and duration time of extraction had effect on $\%$ yield $(\% \mathrm{w} / \mathrm{w})$ of crude extract and the quantity $(\% \mathrm{w} / \mathrm{w})$ of total polyphenols content by areca seed powder. The $\%$ yield of crude extract increased when temperature and duration time of extraction increased. The optimal extraction condition to obtain the highest amount of the crude extract $(9.65 \pm 0.35 \%)$ was at $100^{\circ} \mathrm{C}$ for $45 \mathrm{~min}$. However, the optimal condition of extraction for obtaining the highest $\% \mathrm{w} / \mathrm{w}$ total polyphenols content was at $80^{\circ} \mathrm{C}$ for $45 \mathrm{~min}$. The highest $\% \mathrm{w} / \mathrm{w}$ total polyphenols content equivalent to catechin was $2.76 \pm 0.19 \%$. But this condition did not give the highest $\% \mathrm{w} / \mathrm{w}$ yield $(4.33 \pm 0.26 \%)$. The optimal condition for the highest crude extract $(\% \mathrm{w} / \mathrm{w})$ resulted in more impurities than did the optimal condition for the highest total polyphenols content. Temperature and duration time had effect on total polyphenols extraction. The optimal condition to achieve the highest $\% \mathrm{w} / \mathrm{w}$ total polyphenols content was $80^{\circ} \mathrm{C}$ for $45 \mathrm{~min}$ (Sardsaengjun and Jutiviboonsuk, 2010). Karphrom et al. (2009) studied the antimicrobial of betel nut (Areca catechu Linn.) seed extracts which was found that seeds of betel nuts grown in Nakornchaisri, Nakornbathom province and Banpaew, Samuthprakarn province which had round shaped, immature and mature were extracted with 4 different solvents. They were water, $95 \%$ alcohol, acetone and ethylacetate. These crude extracts were tested for ability to inhibit the growth (MIC) of the pathogenic bacteria; Bacillus cereus ATCC 1729, Staphylococcus aureus ATCC 25923, Escherichia coli ATCC 25922 and Salmonella typhimurium ATCC 13811. It was found that the components in the betel nut seeds were best dissolved in water as the water extraction also yielded the highest amount. It was found that different location affected the \% yield and ability to inhibit the test microorganisms. The betel nut seeds from Nakornchaisri provided higher extract yield and better ability to inhibit the test organisms. These extracts were able to inhibit both gram positive and negative bacteria but prefer to inhibit gram positive while the water and acetone extracts showed the higher inhibition activities. The Minimum Inhibitory Concentration (MIC) of betel nut extracts on all four test organisms were about $0.78 \mathrm{mg} \mathrm{mL}^{-1}$ when tested with Paper Disc Diffusion Technique (Karphrom et al., 2009). Jaiswal et al. (2011) studied the Areca catechu L.; a valauble herbal medicine against different health problem which was found that Areca catechu is a specie of plam grown mainly in Asian countries for seed crop. The chemical constituents of $A$. catech $u$ have been investigated for anti-nematodal/helmintic, anti-oxidant, anti-venom, modulation of phagocytosis, effect on spern motility/catecholamine release as immune suppression, management of psychiatric disorder and Alzheimer's disease. Recent studies have revealed strong molluscidal activity of $A$. catechu against harmful sanils for the control of fascioliasis. Despite its laboratory studies on nemafocidal/helmintic/molluscidal activity arecoline is the major constituents of $A$. catech $u$ for most of their biological effect. $A$. catechu deserves more attention by scientific community and health experts to explore its full range of benefits in welfare of mankind. Adverse effects of oral ingestion of $A$. catechu, causing Oral Submucous Fibrosis (OSF), oral submucous cell carcinoma should be taken inconsideration while their use is recommended in solving different health problem (Jaiswal et al., 2011).

Paul and Zaman (1975) studied the a trial of Mebendazole in trichuriasis (whipworm) infestation in Singapore children which was found that 10 cases of Trichuris infestation in children are described presenting with malaise pica, diarrhea, prolapsed of the rectum, 
anaemia and infection. All children suffered considerably in health by the infection aggravated by protein caloric malnutrition and anaemia. Malay children were mainly affected living in the poor rural areas with poor sanitation. Mebendazole has proved to be effective in the treatment of Trichuriasis in children. Administered orally in tablets it is well tolerated in doses of $100 \mathrm{mg}$ daily for 3 days. Pre and post ova count of the stools while on the drug revealed a reduction rate of almost $100 \%$ in 2 weeks after administration. No side effects were observed with the drug (Paul and Zaman, 1975). Albonico et al. (2003) studied the efficacy of Mebendazole and Levamisole alone or in combination against intestinal nematode infections after repeated targeted Mebendazole treatment in Zanzibar which was found that the overall efficacy of Mebendazole against hookworm infections after periodic chemotherapy is reduced. The efficacy of benzimidazoles in chemotherapy-based control programmes should be monitored closely. Combined treatment with Mebendazole and levamisole may be useful as a tool to delay the development of benzimidazole resistance.

Kafle et al. (2011) studied antifertility effect of Areca catechu in male albino rats which was found that the aim of the present study was to evalue the antifertility activity of Areca catechu in male albino rats. Alcoholic extract of Areca catechu was studied for antifertility at doses 300 and $600 \mathrm{mg} \mathrm{kg}^{-1}$ body weight. Fertility was assessed with mating test. Body weight and weight of the reproductive organs (testis and epididymis) were observed. Biochemical evaluation (total protein content and cholesterol level) and histopathological at $600 \mathrm{mg}$ doses. There was no significant change in the body weight and weight of the reproductive organs (testis and epididymes). Cholesterol in the testis was significant $(\mathrm{p}<0.01)$ increase and total protein content was significantly $(\mathrm{p}<0.01)$ decreased at both doses. Histology of the testis showed reduction in the number of secondary spermatocytes and spermatides. There was a reduction in the number of leydig cells, increase in the diameter of seminiferous tubules with necrotic products and fluid collections at higher dose. Alcoholic extract of Areca catech $u$ showed antifertility activity at 300 and $600 \mathrm{mg} \mathrm{kg}^{-1}$ body weight doses (Kafle et al., 2011). Dawson and Watson (1985) studied the effect of dose form on the bioavailability of Mebendazole in man which was found that four different dose forms of Mebendazole were admistered to human volunteers and urine was collected and assayed for Mebendazole as an oily suspension slightly enhances the bioavailability of the drug, however Mebendazole in human is 2-amino-5(6) [ $\alpha$-hydroxybenzyl] benzimidazole (IV), not 2-amino-5(6) benzoybenzimidazole (II) as previously reported.

\section{MATERIALS AND METHODS}

This research was proceeded during September, 2011 at Primary Health Care Center Mahasarakham Hospital, Mahasarakham, Thailand. The samples were screened purposively relevance to the inclusion and exclusion criteria of 16-65 years old with both genders males and females (not pregnant), non-medicated with any of antihelminthic drugs, non-medicated with any of antibiotic, phenytoin, carbamazepine, no complication of gastrointestinal symptoms, no hepatitis or liver diseases. The collected samples were divided for 5 patients in each group for 4 groups as follows: Placebo control group, treated with Mebendazole experimental group, treated with Thai Traditional Herbal Formula (TTHF) experimental group. The screening method used in this experiment was Ether Formalin Stool Sedimentation Examination which could be used to identify and quantify the EPG (numbers of eggs per gram of feces of infected patient). The study was randomized control trial in the comparative study of the efficacy and side effects. Efficacy was comparable with the reduction (\%) of EPG in each group with treated with Mebendazole and TTHF medicine.

\section{Preparation of Thai Traditional Herbal Formula (TTHF):} TTHF was prepared from 7 herbs as listed from the above. Firstly, the researchers extracted 1. By boiling the immature fruits of 1 with portable water and dried air with the Spraying Technique in order to obtain dry powder of 1 . Then we repeated the same process of extraction with 2,4 to obtain the purified dry powder of 2,4 . Then we took the underground stem of 3 and grated it. The grated 3 was blended in very fine powder. The cuttle bone was was triturated as very fine powder. Then we took the seed of 7. And was triturated as fine powder. We took the fresh fruits of 8 and sliced them to very thin pieces and triturated as the fine powder then mixed it with coconut milk and dried with Spray Drying Technique. Each of them was weighed equally and mixed together with the amount of $72 \mathrm{mg}$ in each prepared dried herbal powder and were filled in $500 \mathrm{mg}$ aseptic capsules by using encapsulation method. All herbs were collected with uncontaminated of bacteria, heavy metals, viruses and free of pesticides with adequate cleansing methods. They were passed through Gamma-rays for aseptic purposes. The process for preparation and purified of all sample capsules were also tested for quality control at the Faculty of Oriental Medicine, Rungsit University, Thailand to assure quality, safety in production. Therefore the products were free from any toxicity. TTHF $(500 \mathrm{mg})$ contained 7 plant species as mentioned earlier used for antihelmintic formulae in this experiment. 


\section{Mebendazole $500 \mathrm{mg}$}

Trade names

Vermox: Tablets, chewable $100 \mathrm{mg}$ (Fig. 5).

Pharmacology: Kills parasitic worms by blocking glucose uptake, thus depleting stored glycogen. Without glycogen, parasite cannot reproduce or survive.

\section{Pharmacokinetics}

Absorption: Mebendazole is poorly absorbed (approximately 5-10\%). $\mathrm{T}_{\max }$ is $0.5-7 \mathrm{~h}$ and $\mathrm{C}_{\max }$ is

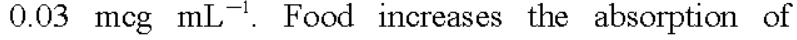
Mebendazole

Distribution: Mebendazole is distributed to serum, cyst fluids, liver, omental fat, pelvic cysts, pulmonary cysts, hepatic cysts and muscles. Mebendazole also crosses the placenta. Protein binding is $90-95 \%$

Metabolism: All metabolites are inactive. The major metabolite is 2-amino-5-benzoylbenzimidazole. Mebendazole is primarily metabolized hepatically.

Elimination: Mebandazole is excreted in the feces and a small amount in urine. The $t_{1 / 2}$ is $2.5-9 \mathrm{~h}$.

Hepatic function impairment: The $t_{1 / 2}$ is prolonged to approximately $30 \mathrm{~h}$.

Indications and usage: Treatment of pinworm (Enterobius vermicularis), round worm (Ascaris lumbricoides), common hookworm (Ancylostoma duodenale), American hookworm (Necator americanus) and whipworm (Trichuris trichiura) in single or mixed parasitic infections.

\section{Dosage and administration}

Trichuriasis, ascariasis and hookworm infection Adults and children: $\mathrm{PO} 100 \mathrm{mg}$ tablet $\mathrm{AM}$ and $\mathrm{PM}$ on 3 consecutive days.

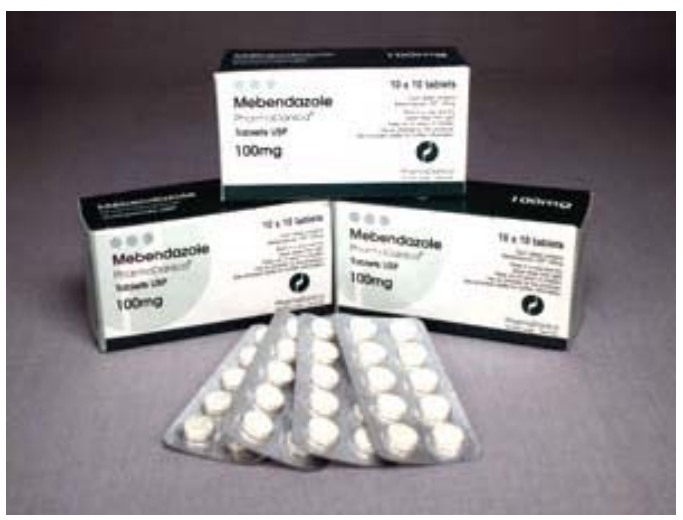

Fig. 5: Mebendazole

\section{Ascaris infection}

Adults and children alternative dose: $\mathrm{PO} 500 \mathrm{mg}$ as single dose.

\section{Enterobiasis}

Adults and children: $\mathrm{PO} 100 \mathrm{mg}$ as single dose.

Storage/stability: Store in tightly closed container at room temperature.

\section{RESULTS AND DISCUSSION}

The collected data were analyzed by Wilcoxon Signed Ranks Test. It showed that the mean difference between EPG of 5 patients treated with Mebendazole $(500 \mathrm{mg}$ ) for 3 days and EPG of 5 patients treated with TTHF (500 mg) for 3 days had showed the statistical significant difference at $\mathrm{p}=0.05$.

The efficacy of Mebendazole ( $500 \mathrm{mg}$ ) measured by the reduction of EPG in mixed helminthes infection patients was $87.50 \%$ and the efficacy of Thai Traditional Herbal Formula TTHF (500 mg) was $93.69 \%$ (Table 1).

The result was also confirmed by Kruskal-Wallis Test which showed the higher mean rank of 13th position in efficacy of TTHF and mean rank of 8th position in efficacy of Mebendazole which showed higher in the efficacy of TTHF (500 mg) in treatment of mixed helminthes infection than treatment with Mebendazole (500 mg) (Fig. 6, Table 2).

Table 1: Willcoxon Signed Ranks Test

\begin{tabular}{lllllll}
\hline & \multicolumn{3}{l}{ Mean EPG } & & & \multicolumn{2}{c}{ Reduction of } \\
No. of & - & & & \multicolumn{2}{c}{ Ren } \\
patients & Placebo & Mebendazole & TTHF & Z & p-values & EPG (\%) \\
\hline 5 & 463.40 & 65.80 & - & -2.023 & - & 87.50 \\
5 & 383.00 & - & 25.00 & - & 0.031 & 93.69 \\
\hline
\end{tabular}

Table 2: Kruskal-Wallis Test

\begin{tabular}{|c|c|c|c|c|c|}
\hline Drugs & $\begin{array}{l}\text { No. of } \\
\text { patients }\end{array}$ & Mean rank & $x^{2}$ & $\mathrm{p}$-value & $\mathrm{CI}(95 \%)$ \\
\hline Mebendazole & 5 & 8 & 12.50 & 0.000 & $0.000-0.181$ \\
\hline TTHF & 5 & 13 & - & - & - \\
\hline
\end{tabular}
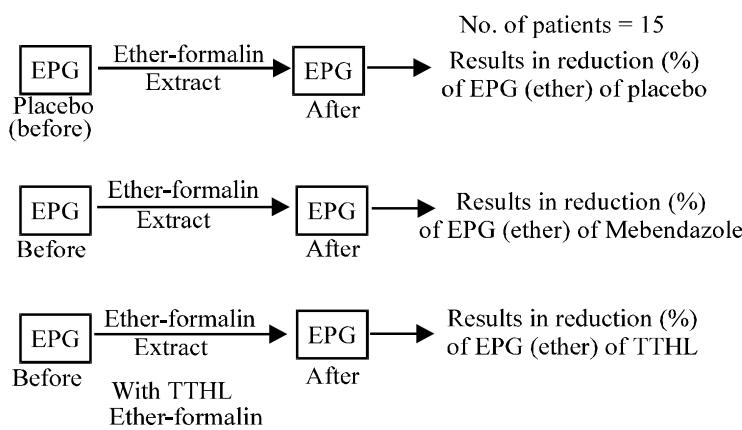

Fig. 6: Conceptual research framework 


\section{CONCLUSION}

This study was carried out 3 days dosages and the EPG (\%) reduction was collected after the 4th day of the experiments in each group of samples. There may be some variations in the results after the first dosage given of each antihelmintic medicine. Because some patients may have parasites presented in different locations of the human bodies such as blood stream, lung liver, etc. Therefore, the efficacy was different in different species of helminthes.

\section{RECOMMENDATIONS}

The extensive study should be recommended in various dosages and repeated dosages of 7,14 and 20 days should be measured the end result of reduction (\%) of Eggs per Gram of Feces (EPG). The result would be more reliable which was suggested to increase the size of samples and in various dosages. The suggestion also aimed to investigate future research of specific species of helminthes for comparative efficacy.

\section{ACKNOWLEDGEMENTS}

This research study was supported for funding by Division of Research Dissemination and Facilitation, Mahasarakham University, Thailand. The research team would like to express the special thank to Assist. Prof. Dr. Supachai Samappito, Prof. Dr. Preecha Prathepa, Sunthorn Dejchai, Mahasarakham University and also to Assoc. Prof. Dr. Surapote Wongyai in preparation of Thai Traditional Herbal Formula, Faculty of Oriental Medicine, Rungsit University, Thailand.

\section{REFERENCES}

Albonico, M., Q. Bickle, M. Ramsan, A. Montresor, L. Savioli and M. Taylor, 2003. The efficacy of mebendazole and levamisole alone or in combination against intestinal nematode infections after repeated targeted mebendazole treatment in Zanzibar. Bulletin World Health Organ., 81: 343-352.

Dawson, M. and T.R. Watson, 1985. The effect of dose form on the bioavailability of mebendazole in man. $\mathrm{Br}$. J. Clin. Pharmacol., 19: 87-90.

Jaiswal, P., P. Kumar, V.K. Singh and D.K. Singh, 2011. Areca catech $\mathrm{L}$.: A valuable herbal medicine against different health problems. Res. J. Med. Plant, 5: 145-152.

Kafle, S., T. Shanbhag, S. Shenoy, A. Amuthan and K. Prabhu et al., 2011. Antifertility effect of Areca catechu in male albino rats. Int. J. Pharma. Sci. Rev. Res., 10: 79-82.

Karphrom, A., S. Suknaisilp, P. Pradeepasaena and S. Tantratian, 2009. Anti-microbial activities of betel nut (Areca catechu Linn.) seed extracts. Proceedings of the International Conference on the Role of Universities in Hands-On Education, August 23-29, 2009, Rajamangala University of Technology Lanna, Chiang-Mai, Thailand, pp: 209-214.

Paul, F.M. and V. Paul, 1975. The trial of mebendazole in trichuriasis (whipworm) infestation in Singapore children. Singapore Med. J., 16: 11-18.

Sardsaengjun, C. and A. Jutiviboonsuk, 2010. The effect of temperature and duration time on polyphenols extract of Areca catechu Linn. Thai. Pharm. Health Sci. J., 5: 14-17. 